\title{
Estudo anatômico e identificaçào química da cera cuticular de folhas de Heliconia aff. tarumaensis Barreiros (Heliconiaceae)
}

\author{
Eduardo Lleras (") \\ Aura M. P. de Diaz (")
}

\begin{abstract}
Resumo
A anatomia foliar e a identificação química da cera cuticular da folha de uma espécie de Heliconia, afim a H. tarumaensis, são apresentadas neste trabalho. A estrutura anatômica da folha é sugestiva de uma planta heliófita, o que concorda bem com os habitats conhecidos para ela. E de notar-se a presença de canais rexígenos, tanto na nervura central quanto no pecíolo. Também são interessantes as baixas proporções de tecido parenquimático, que nunca chegam a ocupar mais da metade da espessura da lâmina. A cera cuticular foi identificada como laurato de n-tetracosila em sua totalidade.
\end{abstract}

\section{INTRODUÇÃo}

Este trabalho foi inspirado pela observação de um pó branco na face inferior de folhas de uma espécie de Heliconia cultivada no "Campus" do INPA. Ao tato, este pó sugeria ser uma cera. O objetivo da pesquisa foi a análise química do produto e a tentativa de determinar o possível local de origem do mesmo mediante o estudo de anatomia foliar.

Estamos designando a espécie em estudo como afim a Heliconia tarumaensis Barreiros (1976), sendo que a descrição de Barreiros não coincide bem com o nosso material. Atualmente está sendo realizada uma pesquisa (Silva \& Lleras, em andamento), para determinar se se trata realmente de $H$. tarumaensis ou uma nova espécie afim a ela.

A espécie estudada aqui é encontrada nc seu habitat natural, em áreas arenosas e úmidas da BR-174 (Rodovia Manaus-Caracaraí). Temos encontrado populações vigorosas ao longo desta estrada entre os $\mathrm{km} 200$ e 350 , existindo uma população grande ao longo da pista aérea de Santo Antônio de Abonari. Ignora-se a proveniência das plantas cultivadas no
"Campus" do INPA, onde são encortradas há mais de três anos.

Com relação à produção de cera. esta não se encontra em regiões das folhas que apresentam clorose. Nas folhas novas que ainda não estão abertas, a cera só aparece nas porções que estão em contato com o ar.

\section{DESCRIÇÃo ANATÔMICA}

PECÍOLO

O pecíolo tem um diâmetro de $3-5 \mathrm{~mm}$, podendo ser um pouco maior nas foihas mais velhas. Epiderme de células pequenas 7-12 $\mu \mathrm{m}$ de largura $X$ 3-8 $\mu \mathrm{m}$ de altura em corte transversal; hipoderme uni-estratificada, células até $100 \mu \mathrm{m}$ de comprimento $\mathrm{X} 36 \mu \mathrm{m}$ de altura. Imediatamente abaixo da derme, existe uma faixa de tecido de suporte misturado com feixes vasculares pequenos. Este mesmo tipo de estrutura tem sido reportado para Zea mays (Esau, 1965). Feixes vasculares colaierais, dispersos no tecido de base; vasos grandes, até $125 \mu \mathrm{m}$ de diâmetro. Lagunas rexigenas presentes, grandes, em corte transversal com diâmetro de até $800 \mu \mathrm{m}$ (Fig. 1), septadas em corte longitudinal, as câmaras assim formadas até $900 \mu \mathrm{m}$ de comprimento; diafragmas das câmaras com células estreladas de ca. $35 \mu \mathrm{m}$ de diâmetro em corte transversal, com meatos intercelulares grandes; em corte longitudinal, o diafragma formado por 3-4 (raramente 5-6) camadas de células reniformes, de ca. $15 \mu \mathrm{m}$ de altura (Fig. 1).

\section{LÂMINA FOLIAR}

Epiderme tanto superior quanto inferior formada por células sinuosas, pequenas (Fig. $3 \mathrm{~A}, \mathrm{~B})$ até $12 \times 12 \times 12 \mu \mathrm{m}$; estômatos pre-

(') - Instituto Nacional de Pesquisas da Amazônia, Manaus. 


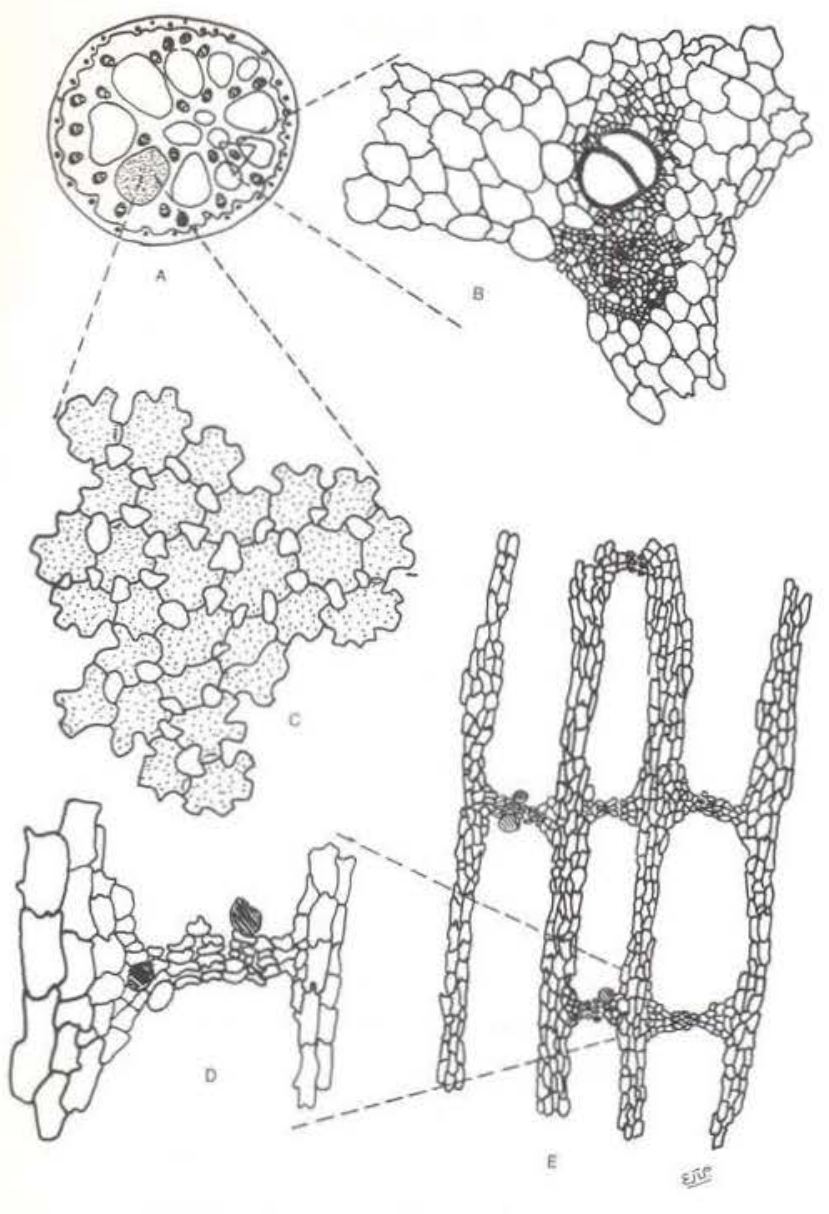

FIGURA 1. Peciolo de Heliconia aff. tarumaensis. A, B e C em secção transversal; D e E em secçāo longitudinal. A, esquema do pecíolo X 7,5; B, detathe de um feixe vasculhar X 100 ; C, detalhe do dia fragma de uma lacuna rexigena X $500 ; D$, detalhe do diafragma (transversal) X 100; Câmaras rexigenas $\mathrm{X} 25$.

sentes só na face inferior da folha, diacíticos (Fig. 2 E, 3), as células guardas com comprimentos de 25-31 $\mu \mathrm{m}$; hipoderme superior formada por uma ou várias camadas, dependendo da distância à nervura central; células evidentes à microscopia óptica da derme, em vista superficial atingindo tamanhos de até $95 \times 95 \mu \mathrm{m}$ (Fig. 2) em corte transversal com tamanhos de até $95 \mu \mathrm{m}$ de comprimento $\times 35$ $\mu \mathrm{m}$ de espessura; hipoderme inferior atingindo tamanhos de até $20 \times 20 \mu \mathrm{m}$; parênquima paliçádico bi-estratificado, as células até 10 $\mu \mathrm{m}$ de comprimento; parênquima lacunoso formado por células globosas, às vezes ramificadas, as células atingem tamanhos de até 20-25 $\mu \mathrm{m}$ de comprimento (Fig. 2). Feixes vasculares colaterais dispersos no mesófilo, com uma pequena faixa colenquimática na parte inferior. A nervura central apresenta faixas colenquimáticas em contato com a epiderme, e lagunas rexígenas semelhantes às apresentadas pelo pecíolo (Fig. 2).

\section{IDENTIFICAÇÃo QUÍMICA DA CERA CUTICULAR}

A cera depositada na cutícula das folhas, em proporção de $0.6 \mathrm{mg} \mid \mathrm{cm}^{2}$ (média tomada de $1000 \mathrm{~cm}^{2}$ em 10 folhas diferentes) está
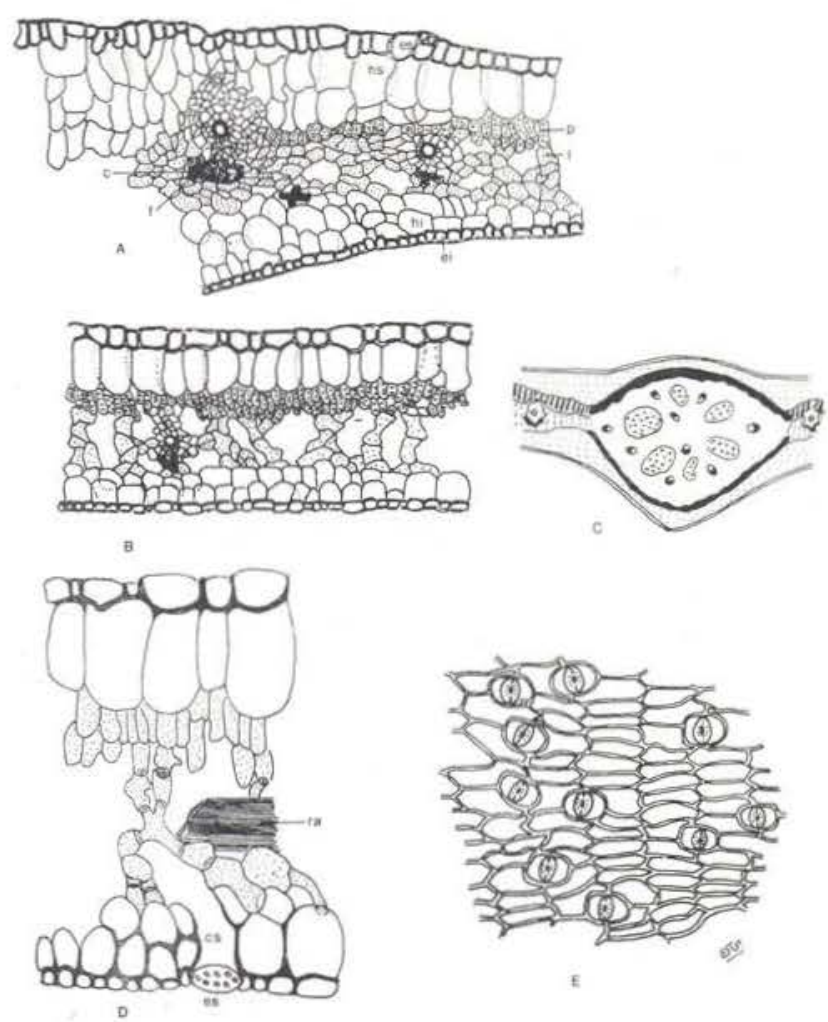

FIGURA 2. Folha de Heliconia aff. tarumaensis. A, D secção transversal; A X 113; D X 250; B, secção longitudinal X 113; C, desenho esquematico da nervura central; E, estomas a nível da primeira camada hipodérmica X 100. Em A e D; c, colênquima; cs, câmara subestomática; ei, epiderme inferior; es, epiderme superior; et, célula estomática; f, floema; hi, hipoderme inferior; hs, hipoderme superior; 1 , parênquima lacunoso; p, parênquima paliçádico; ra, ráfide extra celular. Em C, as áreas pontilhadas são hipoderme; as pretas, colênquima; as linhas escuras, parênquima paliçádico; as linhas discontínuas, parênquima lacunoso; As cruzes, lacunas rexígenas. 
constituída em sua totalidade por laurato de n-tetracosila (I) .

$$
\mathrm{CH}_{3}-\left(\mathrm{CH}_{2}\right)_{10}-\underset{\mathrm{I}}{\mathrm{C}}-\mathrm{O}-\left(\mathrm{CH}_{2}\right)_{23}-\mathrm{CH}_{3}
$$

O laurato de n-tetracosila foi identificado por dados espectrais (IV) e por comparação direta com amostras autênticas dos produtos de saponificação: ácido láurico e n-tetracosanol (Diaz et al., 1977).

\section{MATERIAL E MÉTODOS}

Laurato de n-tetracosila. Cristais brancos, p.f. $67-69^{\circ}$ (benzeno). $\vee \underset{\max }{\mathrm{KBr}}(\mathrm{cm}-1): 2933$, 2899, 2833, 1730, 1475, 1466, 1179, 738.

\section{SAPONIFICAÇÃO DO LAURATO DE N-TETRACOSILA}

Laurato de n-tetracosila (100 mg) foi aquecido sob refluxo durante 2 horas com $30 \mathrm{ml}$ de solução aquosa de hidróxido de potássio

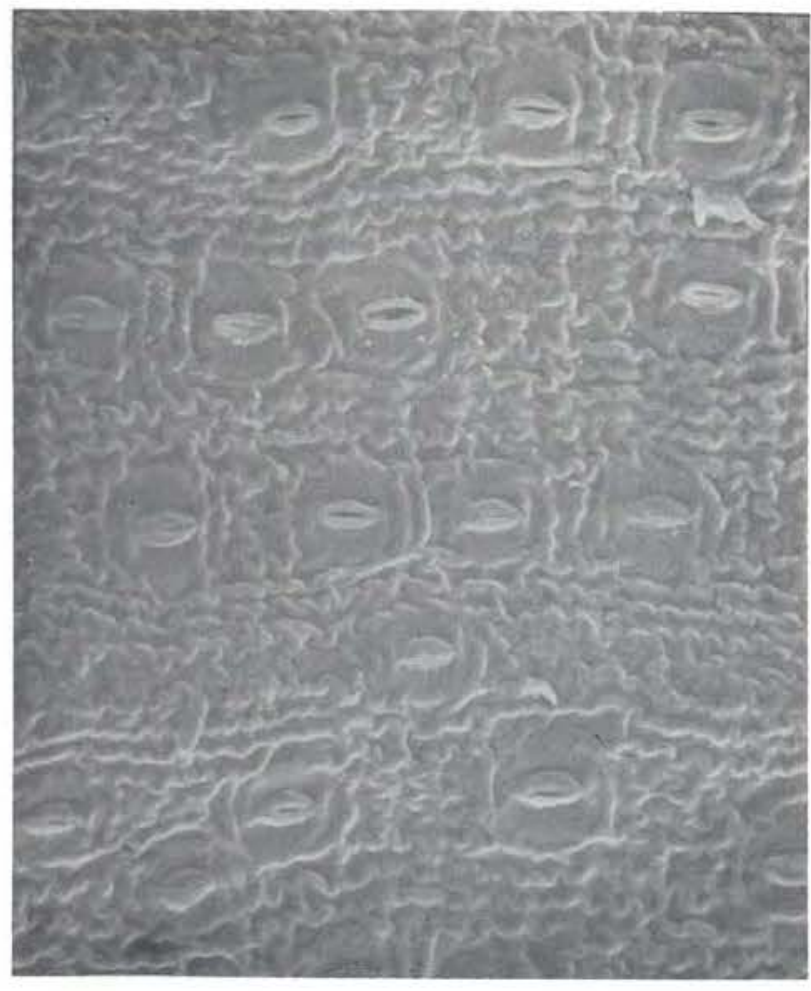

A
$0.5 \mathrm{~N}$. Após acidificação com ácido clorídrico IN, o material orgânico foi extraído com clorofórmio. Por evaporação do solvente cristalizaram $50 \mathrm{mg}$ de n-tetracosanol. Cristais brancos p.f. $74-76^{\circ}$ (clorofórmio). $V_{\max }^{\mathrm{KBr}}\left(\mathrm{cm}^{-1}\right)$ : 3257 . 2899, 2833, 1495, 1464, 1075, 1031, 735. Identificado por comparação direta com amostra autêntica (Diaz et al., 1977).

Cristalização das águas mães de n-tetracosanol deu $30 \mathrm{mg}$ de ácido laurico. Cristais brancos p.f. $46-48^{\circ}$ (benzeno). $V_{\max }^{\mathrm{KBr}}\left(\mathrm{cm}^{-1}\right)$ : $2874,2809,1686,1466,1429,1404,1309,1279$, $1245,1222,1190,935,730$. Identificado por comparação direta com uma amostra autêntica.

\section{DIscussão}

Do ponto de vista anatômico, não foi possível determinar o local certo da origem da cera. A lâmina foliar não apresenta estruturas especializadas dotadas de uma função pro-

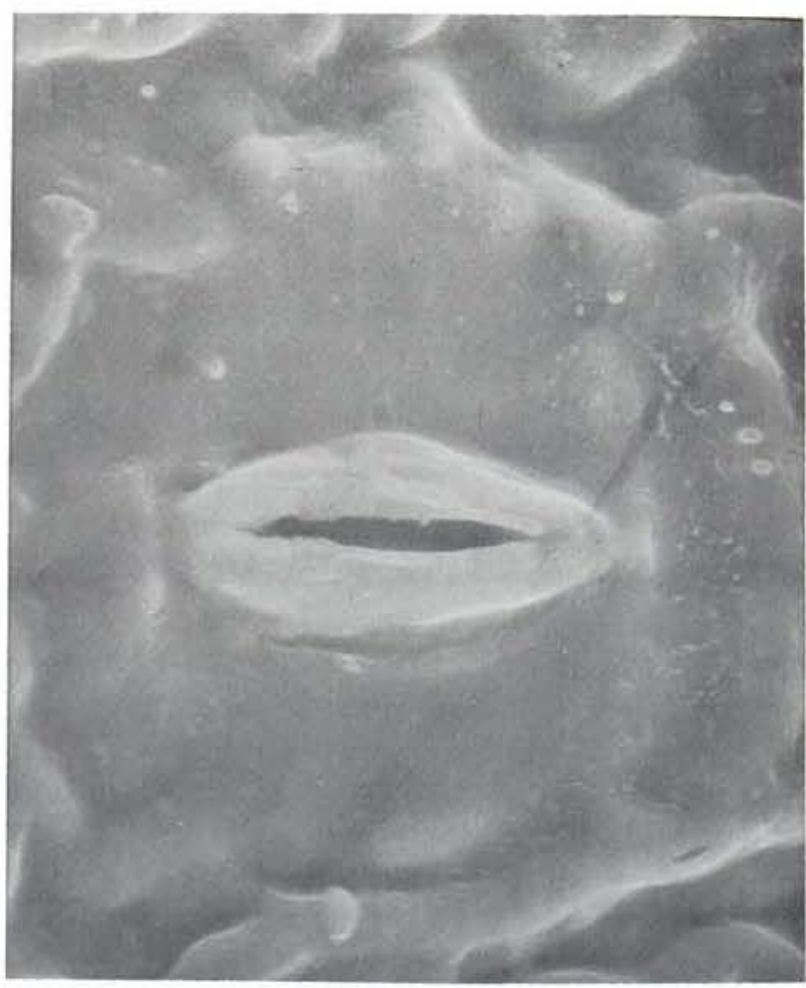

B

FIGURA 3. Fotografias com microscópio de varredura da epiderme inferior de Heliconia aff. tarumaensis. A, X 300; B, detalhe de um estômato X 2000. As células aparecem colapsadas devido a problemas com a técnica de secamento em ponto crítico. (Cortesia do New York Botanical Garden). 
dutora ou excretora da cera; porém, é interessante notar que as células epidérmicas apresentam paredes externas muito finas, o que provavelmente facilita a saida da cera.

A função da cera pode ser de proteção contra fungos (Reynolds, com. pessoal) ou de reflexão da luz solar como proteção contra calor excessivo (Lleras, dados não publicados sobre orientação de folhas de Calathea sp.). Também é possível que a cera tenha uma função de proteção contro insetos, mas não temos dados sobre isto.

A presença de ceras não é exclusiva da espécie estudada; observamos cera também nas brácteas de Heliconia chartacea e Heliconia psittacorum. Atualmente estamos realizando pesquisas sobre estas outras espécies.

Até o presente não encontramos referências na literatura quanto à cera por nós identificada, nem dado algum sobre o possível uso da mesma.

\section{SUMMARY}

Leaf anatomy and chemical identification of cuticular wax of a species of Heliconia related to H. tarumaensis are presented here. The anatomical structure of the leaf is suggestive of a sun plant, and this agrees with the known habitat of the species. Rhexigenous lacunae are present both in the petiole and midrib of the leaf blade. The proportion of photosynthetic tissue is low, never occupying more than $1 / 2$ of the thickness of the leaf. The cuticular wax was identified as n-tetra cosyl laurate.

\section{BIBLIOGRAFIA CITADA}

BARREIROS, H.S

1976 - Heliconiae Novae Americanae (Heliconiaceae). Rodriguésia, 41:129-135.

Diaz, A.M.P. DE; Diaz, P.P.; Ferreira, Z.C.; Gottlieb

O.R.; lima, R.A. de \& Cavalcante, S. de H.

1977 - Ferulic esters from Endlicheria and Ocotea species. Acta Amazonica, $7(2)$ : 292-293.

EsAU, K.

1965 - Plant Anatomy New York. John Wiley \& Sons, $767 \mathrm{p}$. 